ИЗВЕСТИЯ АКАДЕМИИ НАУК ЭСТОНСКОЙ ССР. ТОМ 25 ХИМИЯ * ГЕОЛОГИЯ. 1976, № 4

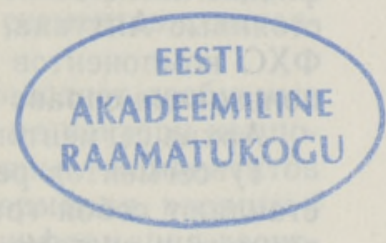

удК $518.5: 533.27+532.77$

О. ААРНА, Ю. КАЛЛАС, Э. УЙБО

\title{
МАШИННЫЙ РАСЧЕТ ФИЗИКО-ХИМИЧЕСКИХ СВОЙСТВ ЖИДКИХ И ГАЗООБРАЗНЫХ СМЕСЕЙ
}

При математическом моделировании химико-технологических процессов необходимо иметь возможность расчета физнко-химических свойств (ФХС) многокомпонентных смесей. Известны некоторые системы машинного расчета ФХС $[1,2,3]$, созданные в США. Более подробно из них описана система AIChE, предназначенная для исследования широкого класса веществ. K сожалению, имеющиеся описания слишком поверхностны для того, чтобы использовать их при разработке новой системы.

Нами была поставлена задача создать систему машинного расчета ФХС многокомпонентных углеводородных смесей, содержащих до 30 компонентов. Система составлена на языке МАЛГОЛ-73 [4,5] для ЭВМ «Минск-22/32»*.

Созданная нами система машинного расчета состоит из следующих основных частей: нентов,

1) архива физико-химических постоянных индивидуальных компо-

2) архива сегментов расчета ФХС,

3) генерирующей программы,

4) результирующей программы.

Оба архива, а также генерирующая программа записаны на магнитную ленту. Связь отдельных блоков в системе иллюстрируется схемой.

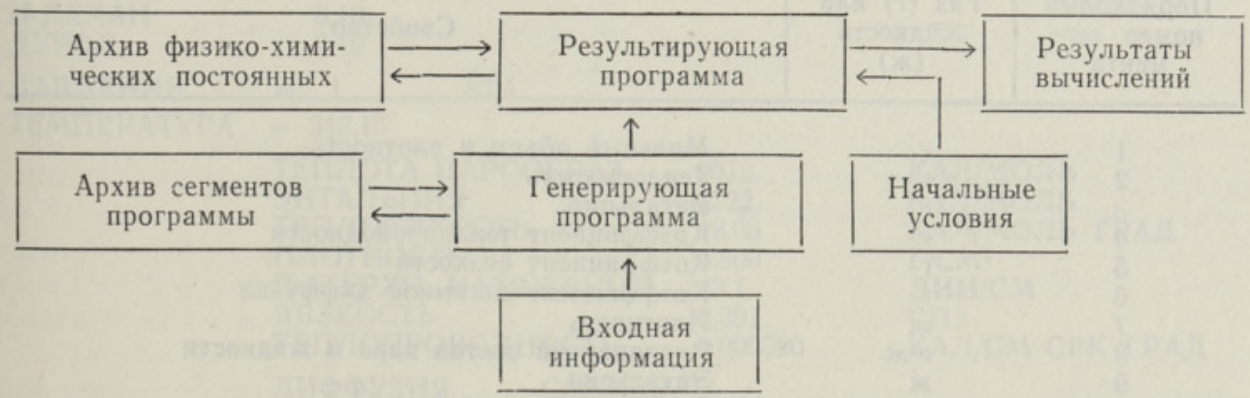

Блоксхема системы.

* В настоящее время описанная ниже система реализована на ЭВМ «Минск-32» и ЕС-1020 с применением языка ФОРТРАН. 
Архив физико-химических постоянных содержит все необходимые физико-химические постоянные компонентов (молекулярные массы, постоянные Антуана, Леннарта-Джонса, Стокмайера и т. п.) для расчета ФХС компонентов и смесей. При составлении архива максимально использована справочная литература.

Архив сегментов программы состоит из трех частей:

1) сегментов результирующей программы (наибольшие из них представляют собой готовые транслированные программы расчета ФХС, например, в системе имеются программы для расчета парожидкостного равновесия [ $\left.\left.{ }^{6}\right]\right)$;

2) оглавления архива сегментов, содержащего начальные адреса сегментов на магнитной ленте;

3) матрицы соединений сегментов $B$, размерностью $m \times n$, где

$b_{i j}=\left\{\begin{array}{l}1, \text { если для расчета свойства } i \text { требуется сегмент } j ; \\ 0, \text { если для расчета свойства } i \text { сегмент } j \text { не требуется } \\ (m-\text { число свойств, } n-\text { число сегментов }) .\end{array}\right.$

Свойства, расчет которых выполняется сегментами архива, представлены в таблице.

\section{Работа системы машинного расчета}

Если составлены архивы физико-химических постоянных и сегментов программы, то на основе списка требуемых физико-химических свойств генерирующей программой составляется результирующая программа (см. схему) «СВОЙСТА СМЕСЕИ». Генерирующая программа компилирует результирующую программу на магнитную ленту и передает управление транслятору. Входной информацией для генерирующей программы является вектор $A=\left(a_{i}\right)_{m}$, элементы которого следующие (см. таблицу) :

если $a_{i}=\left\{\begin{array}{l}1, \text { то } i \text {-тое свойство надо вычислить; } \\ 0, \text { то } i \text {-тое свойство вычислять не надо. }\end{array}\right.$

Результатом умножения вектора $A$ и матрицы соединений $B$ является

Свойства МКС, программы расчета которых содержатся

в архиве сегментов программы

\begin{tabular}{c|c|c}
\hline $\begin{array}{c}\text { Порядковый } \\
\text { номер cег- } \\
\text { мента }\end{array}$ & $\begin{array}{c}\text { Газ (г) или } \\
\text { жикость }\end{array}$ & Свойство \\
\hline
\end{tabular}

\begin{tabular}{|c|c|}
\hline 1 & $\mathrm{r}$ \\
\hline 2 & $r$ \\
\hline 3 & $\Gamma$ \\
\hline 4 & $r$ \\
\hline 5 & r \\
\hline 6 & $\mathrm{r}$ \\
\hline 7 & K \\
\hline 8 & $\Gamma-H$ \\
\hline 9 & K \\
\hline & $\Gamma-\not K$ \\
\hline & $\Gamma-Ж K$ \\
\hline & Ж \\
\hline & ж \\
\hline & Ж \\
\hline & Ж \\
\hline
\end{tabular}

Мольный объем и плотность

Теплоемкость

Энтальпия

Коэффициент теплопроводности

Коэффициент вязкости

Коэффициент взаимной диффузии

Плотность

Равновесный состав пара и жидкости

Энтальпия

Энтальпия парообразования

Поверхностное натяжение

Теплоемкость

Коэффициент вязкости

Коэффициент теплопроводности

Коэффициент взаимной диффузии 
вектор сегментов результирующей программы $C$. Если $C_{j}=1$, то $j$-тый сегмент результирующей программе нужен. По найденному вектору $C$ обращаются к оглавлению архива и находят адреса сегментов, составляющих результирующую программу.

Результирующая программа «свойства смесей» вычисляет требуемые по вектору $A$ свойства смесей. Работа ее следующая: по вектору компонентов смеси (содержащему порядковые номера нужных компонентов согласно архиву физико-химических постоянных) информация, вводимая из архива постоянных, обрабатывается (т. е. лишняя информация гасится). Затем с перфоленты вводятся такие начальные условия, как векторы составов (мольные доли компонентов), давление и температура. Нужные свойства вычисляются и печатаются (см. приложение).

При ложение.

Пример результатов расчета ФХС по программе «СВОИСТВА СМЕСЕИ». При генерировании программы $a_{8}=0$. Состав исходной смеси в мольных долях, температура в К.

ГАЗОВАЯ СМЕСЬ

$\begin{array}{ll}\text { 1-ГЕКСЕН } & 0.10 \\ \text { БЕНЗОЛ } & 0.40 \\ \text { СТИРОЛ } & 0.30 \\ \text { Н-ДЕКАН } & 0.10 \\ \text { ДУРОЛ } & 0.10\end{array}$

ДАВЛЕНИЕ $=1$ ATA

TЕМПЕРАТУРА $=343.15$

\begin{tabular}{|c|c|c|c|c|}
\hline \multicolumn{2}{|c|}{$\begin{array}{l}\text { МОЛЬНЫИ ОБЪЕМ } \\
\text { ПЛОТНОСТЬ } \\
\text { ВЯЗКОСТЬ } \\
\text { ТЕПЛОЕМКОСТЬ } \\
\text { ЭНТАЛЬПИЯ } \\
\text { ТЕПЛОПРОВОДНОСТЬ }\end{array}$} & $\begin{array}{l}28158 \\
0.00350 \\
0.0072 \\
34.64 \\
6291 \\
0.000033\end{array}$ & \multicolumn{2}{|c|}{ 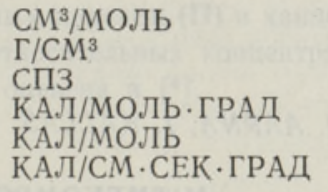 } \\
\hline диФФУзия & $\mathrm{CM}^{2} / \mathrm{CEK}$ & & & \\
\hline $\begin{array}{l}0.0327071 \\
0.0365211 \\
0.0277603 \\
0.0225357 \\
0.0249637\end{array}$ & $\begin{array}{l}0.0365211 \\
0.0411280 \\
0.0309216 \\
0.0248087 \\
0.0276505\end{array}$ & & & $\begin{array}{l}0.0249637 \\
0.0276505 \\
0.0208623 \\
0.0169911 \\
0.0187407\end{array}$ \\
\hline
\end{tabular}

ЖИДКАЯ СМЕСЬ

$\begin{array}{lcc}\text { 1-ГЕКСЕН } & 0.10 \\ \text { БЕНЗОЛ } & 0.40 \\ \text { СТНРОЛ } & 0.30 & \\ \text { Н-ДЕКАН } & 0.10 & \\ \text { ДУРОЛ } & 0.10 & \\ \text { ДАВЛЕНИЕ } & =1 & \\ \text { ТЕМПЕРАТУРА } & =343.15 & \text { АТА }\end{array}$

ТЕПЛОТА ПАРООБРАЗ ЭНТАЛЬПИЯ

ТЕПЛОЕМКОСТЬ

ПЛОТНОСТЬ 0.800

ПОВЕРХН. НАТЯЖЕНИЕ 23.1

ВЯЗКОСТЬ 0.391

ТЕПЛОПРОВОДНОСТЬ 0.000320

дИФФУЗИЯ $\mathrm{CM}^{2} / \mathrm{CEK}$

$0.0000592 \quad 0.0000500$

$0.0000666 \quad 0.0000542$

0.0000353

0.0000373

$0.0000372 \quad 0.0000256$

0.0000449

0.0000256
0.0000228

0.0000370

0.0000294

0.0000206

КАЛ/МОЛЬ

КАЛ/МОЛЬ

КАЛ/МОЛЬ ГРРАД

$\Gamma / \mathrm{CM}^{3}$

ДИН/СМ

СП?

КАЛ/СМ·СЕК·ГРАД

$0.0000348 \quad 0.0000370$

$0.0000320 \quad 0.0000365$

$0.0000220 \quad 0.0000247$

$0.0000196 \quad 0.0000199$

$\begin{array}{ll}0.0000199 & 0.0000194\end{array}$ 


\section{Заключение}

Созданный вариант системы содержит ограниченное число компонентов и сегментов расчета физико-химических свойств, но, используя возможности МАЛГОЛ-системы, его легко расширить, т. е. включить новые сегменты и компоненты. Для экономии памяти и машинного времени предусмотрена возможность апроксимации зависимостей вычисляемых ФХС от температуры (или давления) и состава полиномами Чебышева или квадратичными формами. Результирующие программы легко подключаются к более сложным.

\section{ЛИ ТЕРАТ У Р А}

1. Mead ow s E. L., Chem. Engng Progr., 61, No. 5, 93-108 (1965).

2. He itm a n R. E., H a r ris G. H., Industr. Engng Chem., 60, No. 2, 50-59 (1968).

3. Yen L. C., C a ntwell K. R., Giles B. L., Industr. Engng Chem., 60, No. 2, $70-73$ (1968).

4. Т а м м т Х., Справочные материалы для пользования системой МАЛГОЛ-73. Таллин. 1973.

5. В ых анду Л., С алло К., Юрген сон Р., Система стандартных программ алгоритмического языка МАЛГОЛ. Таллин. 1972.

6. К а л л а с Ю. И., У й б о Э. Э., О методе Вильсона для расчета многокомпонентного равновесия между жидкостью и паром. Тр. Таллинск. политехн. ин-та, № 359, 29-35 (1974).

Таллинский политехнический институт

Поступила в редакцию 1/X 1975

O. AARNA, J. KALLAS, E. UIBO

\section{MITMEKOMPONENDILISTE GAASIDE JA VEDELIKE SEGUDE FUUSIKALIS-KEEMILISTE OMADUSTE ARVUTAMISEST}

Kirjeldatakse füüsikalis-keemiliste omaduste arvutamist elektronarvutil. Koostatud variant arvutab 15 tähtsamat süsivesinike segude omadust. On esitatud 5-komponendilise segu omaduste arvutamise näide.

O. AARNA, J. KALLAS, E. UIBO

\section{COMPUTER CALCULATION OF PROPERTIES OF LIQUID AND GAS MIXTURES}

A system for computer calculation of properties of multicomponent liquid and gas mixtures is described. The present version of system enables to calculate 15 mean properties of hydrocarbon mixtures. An example is presented. 